\title{
Diagnostic Microscopy
}

National Cancer Institute

\section{Source}

National Cancer Institute. Diagnostic Microscopy. NCI Thesaurus. Code C116505.

A diagnostic tool used to view tissues at high magnification, which allows for identification of cellular structures. 